\title{
FENOLOGIA DE PSYCHOTRIA NUDA E P. BRASILIENSIS (RUBIACEAE) EM UMA ÁREA DE FLORESTA ATLÂNTICA NO SUDESTE DO BRASIL
}

\author{
Elisângela Medeiros de Almeida ${ }^{1}$ \\ Maria Alice S. Alves ${ }^{2}$
}

Recebido em 05/10/1999. Aceito em 31/05/2000

\begin{abstract}
RESUMO - (Fenologia de Psychotria nuda e P. brasiliensis (Rubiaceae) em uma área de Floresta Atlântica no sudeste do Brasil). Este estudo descreve os padrões fenológicos de duas espécies simpátricas, Psychotria nuda e $P$. brasiliensis, comparando-as quanto à fenologia e à distribuição espacial e relacionando os eventos fenológicos a fatores abióticos (pluviosidade, temperatura e fotoperíodo) e bióticos (freqüência de polinizadores e de frugívoros). O estudo foi realizado entre agosto/1998 e julho/1999 em uma área de Floresta Atlântica pouco perturbada antropicamente, na Ilha Grande, RJ. Foram feitas observações mensais das fenofases, dos visitantes florais e dos consumidores de frutos de ambas as espécies estudadas. A emissão foliar de $P$. nuda e de $P$. brasiliensis ocorreu de novembro/1998 a maio/1999, havendo correlação positiva significativa desta fenofase com o fotoperíodo, com a pluviosidade média (normais climatológicas) e com a temperatura média (normais climatológicas) para ambas as espécies. O período de floração ocorreu entre março e junho/1999 para $P$. nuda e entre abril e julho/1999 para $P$. brasiliensis. As flores das duas espécies de Psychotria foram visitadas principalmente por uma espécie de beija-flor, Thalurania glaucopis, cujos machos foram os visitantes florais mais comuns em $P$. nuda com 47,2\% (n=682) das visitas, e as fêmeas em $P$. brasiliensis com $85,1 \%(n=1869)$ das visitas. As duas espécies vegetais floresceram no mesmo período, compartilharam as mesmas espécies de polinizadores, mas não necessariamente devem competir por este recurso, rejeitando-se, portanto, a hipótese do compartilhamento do polinizador. O período de frutificação ocorreu ao longo de todo o ano para as duas espécies. A espécie de ave Lipaugus lanioides (Cotingidae) foi o consumidor de frutos mais freqüente em P. brasiliensis. Ambas as espécies de plantas estudadas tiveram padrão de distribuição espacial do tipo agregado e foi evidenciada reprodução vegetativa para um indivíduo de $P$. nuda. Este estudo sugere que ambas as espécies de Psychotria são importantes recursos para espécies de aves de Floresta Atlântica.
\end{abstract}

Palavras-chave - Psychotria, fenologia, distribuição espacial, Mata Atlântica, Brasil

ABSTRACT - (Phenology of Psychotria nuda and P. brasiliensis (Rubiaceae) in an area of the Atlantic Forest, Southeast of Brazil). We compared two sympatric species of Psychotria (P. brasiliensis and P. nuda), regarding phenology and spatial distribution. The phenological events were associated with abiotic factors (rainfall, temperature and photoperiod) and biotic factors (pollinators and frugivores). We carried out the study between August/1998 and July/1999 in an undisturbed area of the Atlantic Forest at Ilha Grande, Rio de Janeiro. We made phenological

1 Programa de Pós-Graduação em Ecologia da Universidade Federal do Rio de Janeiro, RJ, Brasil

2 Setor de Ecologia, Departamento de Biologia Animal e Vegetal, Instituto de Biologia Roberto Alcântara Gomes, Universidade do Estado do Rio de Janeiro, Rua São Francisco Xavier 524, CEP 20550-011, Rio de Janeiro, RJ, Brasil. e-mail: epalmeida@hotmail.com ou mase@uerj.br 
observations and also recorded the species visiting the flowers and eating the fruits of both plant species. The production of new leaves occurred from November/1998 to May/1999 for both species. There was a positive correlation between photoperiod, rainfall and temperature (climatological means) and leafing period. The flowering period was between March and June for P. nuda and, April and July for P. brasiliensis. Psychotria nuda was visited mainly by males of an species of hummingbird, Thalurania glaucopis (Trochilidae) (47,2\%; n=682), while $P$. brasiliensis was visited by females $(85,1 \% ; \mathrm{n}=1869)$ of this hummingbird species. Both species flowered in the same period, used the same pollinator, but may not compete for this resource, thus we rejected the "sharedpollinator" hypothesis. The fruiting period ocurred all year round for P. nuda and P. brasiliensis. Lipaugus lanioides, was the most frequent frugivore in P. brasiliensis. Psychotria nuda and P. brasiliensis had clumped distribution, apparently due to vegetative reproduction, mostly by $P$. nuda. This study suggests that both species of Psychotria are important resources for Atlantic Rain Forest bird species.

Key words - Psychotria, phenology, spatial distribution, Atlantic Forest, Brazil

\section{Introdução}

A fenologia das plantas, que diz respeito ao período e à duração de eventos como a floração, a frutificação e a emissão foliar, é pouco conhecida para muitas espécies de florestas tropicais úmidas, embora nestes ecossistemas ocorra a maior diversidade de padrões fenológicos (Newstrom et al. 1994). A observação fenológica, obtida de forma sistemática, reúne informações sobre o estabelecimento de espécies, o período de crescimento, o período de reprodução e a disponibilidade de recursos alimentares (Morellato \& Leitão-Filho 1992), que podem estar associados a mudanças na qualidade e à abundância de recursos, como luz e água (Morellato 1990).

Como as populações vegetais e animais possuem inúmeras relações (e.g. planta-polinizador e planta-dispersor) e influenciam-se reciprocamente, a dinâmica da vegetação pode estar ajustada ou relacionada à dinâmica dos consumidores primários (Howe \& Primack 1975; Feinsinger et al. 1985; Bawa 1990; Morellato 1992; Morellato \& Leitão-Filho 1992; Galetti \& Pizo 1996). Vários estudos consideram os padrões temporais de floração como resultado da coevolução de plantas com os polinizadores e predadores de sementes (Borchert 1983). Alguns autores hipotetizam que o período de floração deve ser diferente para espécies vegetais que são visitadas pelos mesmos polinizadores (hipótese do compartilhamento do polinizador), o que minimizaria a competição por este recurso e maximizaria a aptidão da espécie vegetal (Gentry 1974; Stiles 1975; Campbell 1985; Araújo et al. 1994; Wright \& Calderon 1995).

Animais dispersores e predadores de frutos e sementes são fatores seletivos importantes na determinação dos padrões de frutificação das plantas (Morelatto \& Leitão-Filho 1992). Hipóteses de coevolução planta-dispersor (Snow 1971; Howe \& Smallwood 1982) supõem duas situações contrastantes: algumas plantas, denominadas plantas de baixo investimento, produziriam grande número de pequenos frutos, nutricionalmente pobres, atraindo grande variedade de dispersores de baixa qualidade, como aves oportunistas ou generalistas, que completam sua dieta com frutos. Enquanto outras plantas, denominadas plantas de alto investimento, produziriam número reduzido de grandes frutos, nutricionalmente superiores, por extenso período de frutificação, atraindo limitado número de frugívoros especialistas que fariam dispersão de alta qualidade.

O gênero Psychotria L. é o maior da família Rubiaceae, com cerca de 1.600 espécies de distribuição tropical, havendo, entretanto, estudos sobre a fenologia de poucas espécies deste gênero (Wright 1991; Ibarra Manriquez \& Sinaca Colin 1995; Tissue \& Wright 1995; Aide \& Angulo Sandoval 1997; Grandisoli 1997; Pachecho \& Grau 1997). As espécies de Psychotria constituem fontes de néctar e de frutos para animais, fazendo parte dos recursos 
utilizados pela fauna de diversas comunidades de florestas semidecíduas (Morellato 1992; Grandisoli 1997), de Floresta Subtropical Montana (Pachecho \& Grau 1997) e de Floresta Atlântica (Lima 1988).

Neste estudo são descritos os padrões fenológicos de duas espécies simpátricas do gênero Psychotria (P. brasiliensis e P. nuda) em uma área de Floresta Atlântica da Ilha Grande no Rio de Janeiro, com os objetivos de: a) comparar as duas espécies quanto à fenologia e ao padrão de distribuição espacial; b) relacionar os eventos fenológicos a fatores abióticos (pluviosidade, temperatura e fotoperíodo) e bióticos (frequência de polinizadores e de frugívoros); c) investigar em qual modelo de coevolução planta-dispersor (plantas de baixo investimento, plantas de alto investimento) cada uma das espécies vegetais se adequa; d) relacionar os dados de floração e dos visitantes florais de ambas as espécies de plantas com a hipótese do compartilhamento do polinizador. De acordo com esta hipótese, esperar-se-ia que, caso estas espécies compartilhassem os mesmos visitantes florais, os períodos de floração deveriam ser distintos.

\section{Material e métodos}

Área de estudo - O estudo foi realizado em uma área de Floresta Atlântica pouco perturbada antropicamente, na Ilha Grande, Rio de Janeiro (2310'571'S e 4412'549'W). A ilha, que possui área de 19.000 ha, é coberta por Floresta Atlântica em diferentes estádios de regeneração, devido a distúrbios causados por diversas culturas de plantas, como café e cana-de-açúcar, que cessaram com a criação de diversas áreas de preservação, tais como a Reserva Biológica Estadual da Praia do Sul (Araújo e Oliveira 1988) e o Parque Estadual da Ilha Grande, onde foi realizado o estudo.

As comunidades vegetais da mata de encosta são as menos conhecidas botanicamente em função da dificuldade de acesso. Uma lista preliminar de Araújo e Oliveira (1988) para a
Reserva Biológica Estadual da Praia do Sul cita 104 espécies vegetais encontradas na mata de encosta, sendo que as cinco famílias com o maior número de espécies foram Rubiaceae (12 espécies), Melastomataceae ( 9 espécies), Piperaceae (7 espécies), Palmae (6 espécies) e Orchidaceae (5 espécies).

A altitude da área de estudo varia de 140 a $260 \mathrm{~m}$ (dados deste trabalho) e a altura da canópia de 25 a 30m, com árvores com diâmetro de até $1,20 \mathrm{~m}$ (Vera y Conde, dados não publicados). Não há estudos de levantamentos florísticos nesta área, exceto o realizado por Almeida et al. (1998) que trabalharam com comunidades de bromeliáceas. Estes autores encontraram alta densidade de indivíduos por hectare, distribuídos em diferentes estratos verticais. Os gêneros mais freqüentes foram Vriesea e Neoregelia, representados, além de outras, por espécies de grande porte como $V$. gigantea, $N$. johannis e $V$. procera que, em áreas antropicamente modificadas, são pouco comuns.

O clima da região é quente-úmido, com temperatura média anual de $23^{\circ} \mathrm{C}$ e pluviosidade anual de aproximadamente $2.200 \mathrm{~mm}$ (dados fornecidos pela Fundação Instituto de Desenvolvimento Econômico e Social do Rio de Janeiro).

Metodologia - As observações das fenofases de $P$. nuda e de $P$. brasiliensis foram realizadas mensalmente, entre agosto/1998 e julho/1999, ao longo de uma transecção de $1.000 \mathrm{~m}$ compr. por $10 \mathrm{~m}$ larg., totalizando $1 \mathrm{ha}$ de área amostral. Neste período foram registrados: a) número de flores abertas; b) número de frutos verdes; c) número de frutos maduros e d) presença ou não de folhas novas em 24 indivíduos de $P$. nuda e em 19 de $P$. brasiliensis marcados aleatoriamente dentro do transecto (os números amostrais foram diferentes devido a perda total ou parcial de alguns indivíduos de $P$. brasiliensis causada por quedas de árvores ou fatores fora de controle pessoal).

Foram realizadas observações diurnas dos consumidores de frutos de $P$. nuda e $P$. brasiliensis entre agosto e dezembro/1998. Es- 
tas observações foram feitas em um dia por mês para cada espécie, escolhendo-se três ou até quatro indivíduos que se encontravam no campo de visão do observador e que tinham frutos maduros, totalizando 15 indivíduos para cada espécie. Os visitantes florais foram observados em 10 indivíduos de $P$. nuda entre março e abril/ 1999 e em sete indivíduos de $P$. brasiliensis entre maio e junho/1999. Estas observações foram realizadas utilizando-se o método do indivíduo focal (Altman 1974), ou seja, um indivíduo por dia era observado. As sessões de observação dos visitantes florais e dos consumidores de frutos das espécies de Psychotria duraram $30 \mathrm{~min}$, com intervalos de $30 \mathrm{~min}$, no período de 06:00h às 17:30h. A freqüência de visitação dos potenciais polinizadores e dispersores foi avaliada registrando-se número de flores visitadas ou frutos ingeridos, a ordem, a família ou o gênero e, quando possível, a espécie do visitante.

Para se relacionar o tamanho dos frutos maduros de $P$. nuda e de $P$. brasiliensis com outras espécies frutíferas de Floresta Atlântica, foi medido o maior comprimento dos frutos maduros das duas espécies, utilizando-se paquímetro com precisão de $0,1 \mathrm{~mm}$, e comparados com a ordenação de tamanhos de frutos feita por Correia (1997), que trabalhou com uma comunidade vegetal de Floresta Atlântica.

Foi utilizada a correlação de Spearman $\left(r_{s}\right)$ para relacionar os fatores abióticos (fotoperíodo, pluviosidade do período de estudo, normais climatológicas da temperatura e da pluviosidade) e as fenofases (número de flores abertas, de frutos verdes, de frutos maduros e o número de indivíduos com emissão de folhas novas) de $P$. nuda e de $P$. brasiliensis. Este teste estatístico foi utilizado porque os dados fenológicos não apresentaram distribuição normal (Zar 1999). O teste t de Student (Zar 1999) foi utilizado para comparar o comprimento médio dos frutos maduros de ambas as espécies estudadas. Médias \pm dp (desvio padrão) são apresentados ao longo do texto.

Foi avaliado o padrão de distribuição espa- cial de cada espécie pelo Índice de Dispersão Padronizado de Morisita (Brower \& Zar 1984). Para isto, foram amostradas duas grades de 3,8ha separadas entre si por distância de 250m. Em cada grade foram sorteadas 20 parcelas diferentes de $5 \times 5 \mathrm{~m}\left(500 \mathrm{~m}^{2}\right)$. Nas parcelas foram contados e mapeados todos os indivíduos das duas espécies, com altura maior do que $0,5 \mathrm{~m}$. A densidade das duas espécies na área foi estimada contando-se o número de indivíduos de cada espécie em uma parcela de 1 ha (correspondente à área que foi utilizada para o transecto). Como existem evidências de reprodução vegetativa neste gênero (Grandisoli 1997), para evitar erros de amostragem, considerou-se como mesmo indivíduo as plantas que estavam distantes em um raio de até $0,5 \mathrm{~m}$ de outra da mesma espécie.

\section{Resultados}

O período de crescimento (emissão foliar) de Psychotria nuda e de P. brasiliensis ocorreu de novembro/1998 a maio/1999, coincidente com a estação úmida e com os meses mais quentes e de maior fotoperíodo (Fig. 1 e 2). Esta fenofase correlacionou-se significativa e positivamente com o fotoperíodo, com a pluviosidade média e com a temperatura média das normais climatológicas (Tab. 1), para ambas as espécies estudadas. Entretanto, não houve correlação significativa com a pluviosidade do período de estudo. Entre dezembro e fevereiro, $100 \%$ dos indivíduos marcados de $P$. nuda estavam com emissão de folhas novas, enquanto para $P$. brasiliensis a maior percentagem de indivíduos com folhas novas ocorreu em janeiro (Fig. 3).

Houve $100 \%$ de sobreposição na extensão do período de emissão de folhas novas das duas espécies (Fig. 2 e 3), mas as duas populações iniciaram a floração em diferentes meses, ao final da estação chuvosa. O período de floração da população de $P$. nuda ocorreu de março até junho (Fig. 2). A população de $P$. brasiliensis iniciou o período de floração em abril, encerrando-o no mês de julho (Fig. 2). O número máxi- 
A

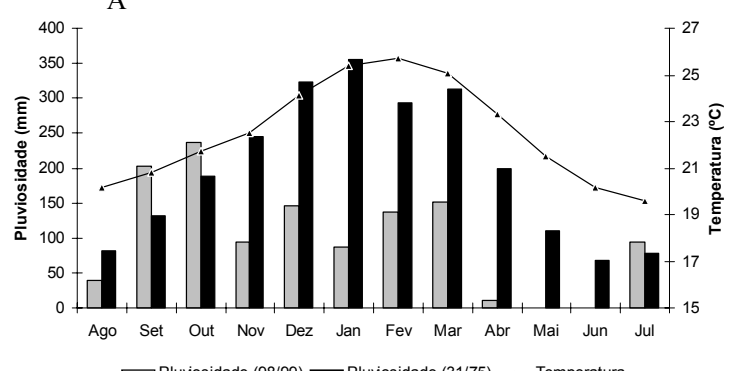

$\square$ Pluviosidade (98/99) Pluviosidade (31/75) —-_Temperatura

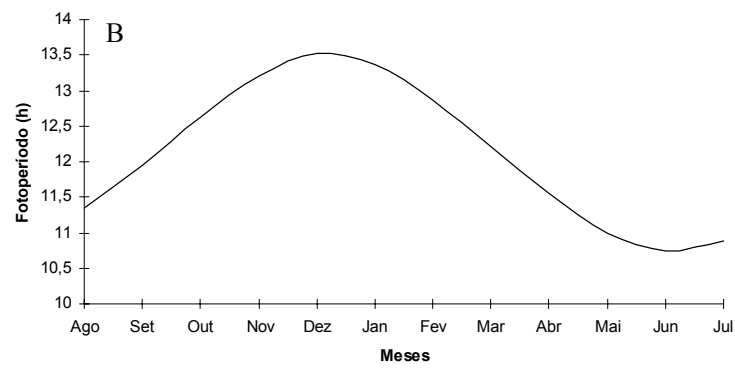

Figura 1. A) Pluviosidade média do período de estudo (agosto/1998 a julho/1999) (dados fornecidos pelo NUCLEN) e pluviosidade média e temperatura média do período de janeiro/1931 a dezembro/1975 (normais climatológicas) (dados fornecidos pela Fundação Instituto de Desenvolvimento Econômico e Social do Rio de Janeiro) da baía da Ilha Grande, RJ. B) Fotoperíodo entre agosto/1998 e julho/1999 para o Estado do Rio de Janeiro. mo de produção de flores ocorreu em meses diferentes para ambas as espécies estudadas (Fig. 4), sendo em abril para P. nuda (média de 4,0 \pm $5,3$ flores abertas por indivíduo; $\mathrm{n}=24)$ e em maio para $P$. brasiliensis (média de 2,6 $\pm 6,1$ flores abertas por indivíduo; $\mathrm{n}=19$ ). Porém, a maior percentagem de indivíduos com flores foi em maio tanto para $P$. nuda $(62,5 \%, \mathrm{n}=24)$ quanto para $P$. brasiliensis $(52,6 \%, \mathrm{n}=19)$ (Fig. 2). Os visitantes de ambas as espécies foram beijaflores e insetos das ordens Hymenoptera e Lepidoptera. Psychotria nuda foi visitada principalmente por machos de Thalurania glaucopis (Aves: Trochilidae) $(47,2 \%, \mathrm{n}=682)$, seguido por Euglossa sp. $(19 \%, \mathrm{n}=682)$, por fêmeas de $T$. glaucopis $(16,6 \%, \mathrm{n}=682)$, por Trigona spinipes $(6 \%, \mathrm{n}=682)$ e por espécies de borboletas das famílias Nymphalidae $(5,6 \%$, $\mathrm{n}=682)$ e Hesperidae $(5,6 \%, \mathrm{n}=682)$. Psychotria brasiliensis foi mais visitada por fêmeas de $T$. glaucopis $(85,1 \%, \mathrm{n}=1869)$, seguida por machos desta espécie $(9,6 \%, n=1869)$, por espécies de borboletas da família Hesperidae $(2,7 \%, \mathrm{n}=1869)$ e Papilionidae $(1,7 \%, \mathrm{n}=1869)$, por Trigona

\begin{tabular}{|c|c|c|c|c|c|c|c|c|c|c|c|c|}
\hline & דים & (95.8) & (91.7) & (87.5) & (83.3) & (75.0) & -(54.2) & די--ים & (25.0) & ד----י & ד(66.7) & (87.5) \\
\hline & $\begin{array}{c}* * * * * * \\
(8.3)\end{array}$ & $\begin{array}{l}* * * * * * \\
(29.2)\end{array}$ & $\begin{array}{c}* * * * * * \\
(8.3)\end{array}$ & $\begin{array}{l}* * * * * \\
(12.5)\end{array}$ & $\begin{array}{l}* * * * * * \\
(20.8)\end{array}$ & $\begin{array}{l}* * * * * \\
(25.0)\end{array}$ & $\begin{array}{l}* * * * * \\
(16.7)\end{array}$ & $\begin{array}{l}* * * * * * \\
(16.7)\end{array}$ & $\begin{array}{l}* * * * * \\
(16.7)\end{array}$ & $\begin{array}{c}* * * * * * \\
(8.3)\end{array}$ & $\begin{array}{c}* * * * * * \\
(8.3)\end{array}$ & \\
\hline \multirow{4}{*}{$\begin{array}{c}\text { P. nuda } \\
(\mathrm{n}=24)\end{array}$} & & & & $\begin{array}{l}-.--\cdot-\cdot \\
(45.8)\end{array}$ & $\begin{array}{l}-.-.-.-. \\
(100)\end{array}$ & $\begin{array}{l}-.-.-\cdot- \\
(100)\end{array}$ & $\begin{array}{l}-. \cdot-\cdot-\cdot . \\
(100)\end{array}$ & $\begin{array}{l}-.-\cdot-\cdot-. \\
(45.8)\end{array}$ & $\begin{array}{l}-.-.-.-. \\
(37.5)\end{array}$ & $\begin{array}{l}-. .-\cdot-\cdot . \\
(12.5)\end{array}$ & & \\
\hline & & & & & & & & $\begin{array}{l}++++ \\
(33.3)\end{array}$ & $\begin{array}{l}++++ \\
(58.3)\end{array}$ & $\begin{array}{l}+++++ \\
(62.5)\end{array}$ & $\begin{array}{c}++++ \\
(4.2)\end{array}$ & \\
\hline & (94.7) & (89.5) & (89.5) & 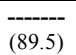 & דים & (79.0) & (73.7) & $\overline{(42.1)}$ & - & & $\overline{(15.8)}$ & (84.2) \\
\hline & & $\begin{array}{l}* * * * * * \\
(10.5)\end{array}$ & & & $\begin{array}{l}* * * * * * \\
(26.3)\end{array}$ & $\begin{array}{l}* * * * * * \\
(15.8)\end{array}$ & $\begin{array}{l}* * * * * \\
(31.6)\end{array}$ & & & & & \\
\hline \multirow{4}{*}{$\begin{array}{c}\text { P. brasiliensis } \\
(\mathrm{n}=19)\end{array}$} & & & & $\begin{array}{l}-\because-\cdots-.-. \\
(36.8)\end{array}$ & $\begin{array}{l}-.--.--. \\
(36.8)\end{array}$ & $\begin{array}{l}-\because-\cdots-\cdot \\
(100)\end{array}$ & $\begin{array}{c}-\because-.-.- \\
(94.7)\end{array}$ & $\begin{array}{l}-.---.- \\
(52.6)\end{array}$ & $\begin{array}{l}-\cdots-\cdots .-. \\
(36.8)\end{array}$ & 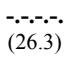 & & \\
\hline & & & & & & & & & $\begin{array}{l}++++ \\
(10.5)\end{array}$ & $\begin{array}{l}++++ \\
(52.6)\end{array}$ & $\begin{array}{l}++++ \\
(42.1)\end{array}$ & $\begin{array}{l}++++ \\
(10.5)\end{array}$ \\
\hline & Ago & Set & Out & Nov & Dez & Jan & $\mathrm{Fev}$ & Mar & Abr & Mai & Jun & Jul \\
\hline & & & 1998 & & & & & 1999 & & & & \\
\hline
\end{tabular}

Figura 2. Caracterização das fenofases de Psychotria nuda e de P. brasiliensis no período de agosto/1998 a julho/1999, em área de Floresta Atlântica, Ilha Grande, RJ. Entre parêntesis a proporção de indivíduos nas respectivas fenofases. +++ flores; ------ frutos verdes; **** frutos maduros; -.-.-.- emissão foliar. 
Tabela 1: Valores significativos da correlação de Spearman entre os fatores abióticos (temperatura, pluviosidade, fotoperíodo) e as fenofases de Psychotria nuda e P. brasiliensis amostradas. Entre parênteses o valor do índice de correlação de Spearman $\left(\mathrm{r}_{\mathrm{s}}\right) .-=$ valores não significativos.

\begin{tabular}{|c|c|c|c|c|}
\hline \multirow[b]{2}{*}{ Espécies } & \multicolumn{4}{|c|}{ Fenofases } \\
\hline & $\begin{array}{l}\text { Emissão } \\
\text { foliar }\end{array}$ & $\begin{array}{l}\text { Flores } \\
\text { abertas }\end{array}$ & $\begin{array}{c}\text { Frutos } \\
\text { imaturos }\end{array}$ & $\begin{array}{c}\text { Futos } \\
\text { maduros }\end{array}$ \\
\hline $\begin{array}{l}\text { Psychotria nuda } \\
\quad(\mathrm{n}=24)\end{array}$ & $\begin{array}{ll}\text { Temp. } & (0,65) \\
\text { Pluv. } & (0,89) \\
\text { Fotop. } & (0,77)\end{array}$ & $\begin{array}{l}- \\
- \\
-\end{array}$ & $\begin{array}{c}\text { Temp. }(-0,66) \\
- \\
-\end{array}$ & $\begin{array}{ll}\text { Temp. } & (0,63) \\
\text { Pluv. } & (0,61) \\
\text { Fotop. } & (0,69)\end{array}$ \\
\hline $\begin{array}{l}\text { Psychotria brasiliensis } \\
\qquad(\mathrm{n}=19)\end{array}$ & $\begin{array}{ll}\text { Temp. } & (0,93) \\
\text { Pluv. } & (0,87) \\
\text { Fotop. } & (0,66)\end{array}$ & \begin{tabular}{l}
\multicolumn{2}{c}{-} \\
Pluv. $\quad(-0,59)$ \\
Fotop. $(-0,75)$
\end{tabular} & $\begin{array}{l}- \\
- \\
-\end{array}$ & \begin{tabular}{l}
\multicolumn{2}{c}{-} \\
Pluv. $(0,61)$ \\
Fotop. $(0,67)$
\end{tabular} \\
\hline
\end{tabular}

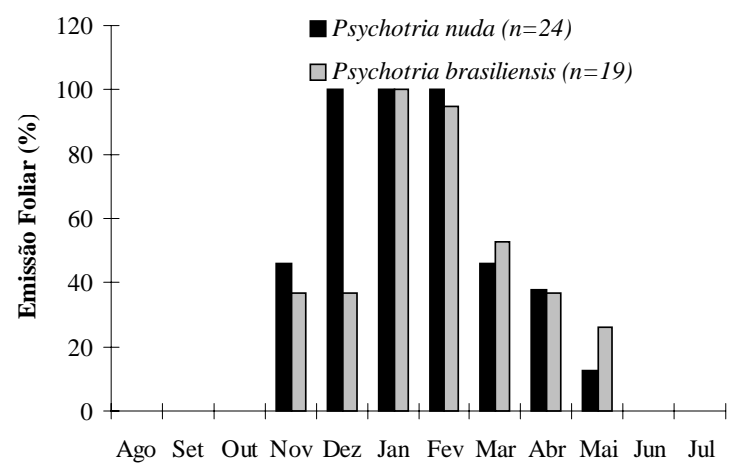

Figura 3. Frequência de indivíduos de Psychotria nuda e $P$. brasiliensis com emissão foliar entre agosto/1998 e julho/ 1999, em área de Floresta Atlântica, Ilha Grande, RJ.

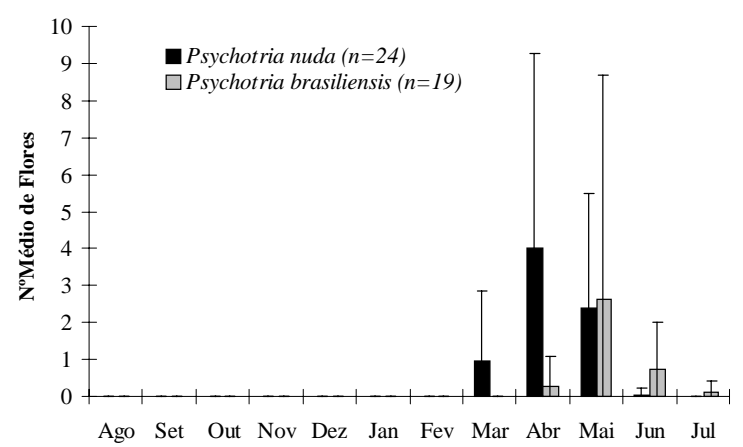

Figura 4. Número médio e erros-padrão de flores abertas por indivíduo de Psychotria nuda e P. brasiliensis no período de agosto/1998 a julho/1999, em área de Floresta Atlântica, Ilha Grande, RJ. spinipes $(0,6 \%, \mathrm{n}=1869)$ e por Euglossa $\mathrm{sp}$. $(0,3 \%, \mathrm{n}=1869)$.

Houve correlação negativa significativa entre o número de flores abertas de $P$. brasiliensis com o fotoperíodo e com a pluviosidade das normais climatológicas (Tab.1). No entanto, não houve correlação significativa entre esta fenofase e a pluviosidade do período de estudo. Os fatores abióticos analisados não tiveram correlação significativa com este período fenológico de $P$. nuda.

O período de frutificação foi o evento fenológico de maior duração nas duas espécies (Fig. 2) e mais de $50 \%$ dos indivíduos estavam com frutos verdes na maior parte do período de frutificação, revelando elevada sincronia entre os indivíduos nas populações de ambas as espécies de Psychotria (Fig. 2). Psychotria nuda teve maior número de frutos maduros entre dezembro e fevereiro/1999 (Fig. 5), porém a maior percentagem de indivíduos nesta fenofase foi em setembro/1998 (Fig. 2). A população de $P$. brasiliensis teve maior número médio de frutos maduros em dezembro/1998 (Fig. 5) e maior percentagem de indivíduos desta espécie nesta fenofase em fevereiro (Fig. 2). O número médio de frutos maduros de $P$. nuda e $P$. brasiliensis foi maior em meses de alta pluviosidade, temperatura e fotoperíodo (Fig. 1 e 5), correlacionando-se significativa e positiva- 


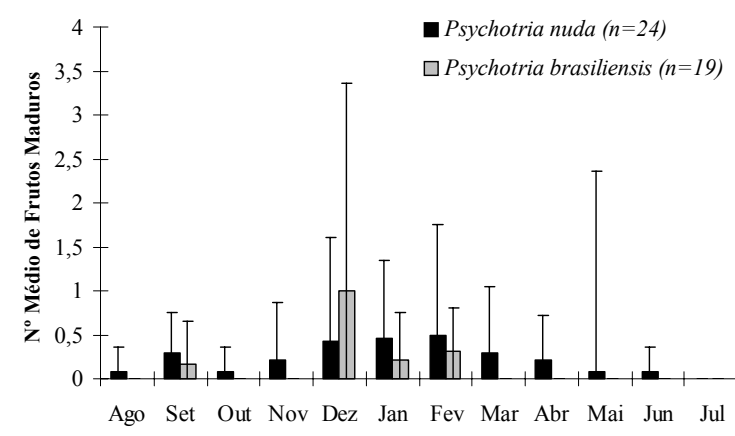

Figura 5. Número médio e erros-padrão de frutos maduros por indivíduo de Psychotria nuda e P. brasiliensis no período de agosto/1998 a julho/1999, em área de Floresta Atlântica, Ilha Grande, RJ.

mente tanto com o fotoperíodo, quanto com a pluviosidade das normais climatológicas, mas não com a pluviosidade do período de estudo (Tab. 1). O número de frutos maduros de $P$. nuda correlacionou-se também com a temperatura, enquanto os frutos verdes desta espécie correlacionaram-se negativamente com este fator (Tab. 1).

Lipaugus lanioides (Aves: Cotingidae) foi o consumidor de frutos mais freqüente de $P$. brasiliensis $(63,6 \%, \mathrm{n}=11)$, seguido de Baryphthengus ruficapillus (Aves: Momotidae) $(27,3 \%, \mathrm{n}=11)$ e de Saltator similis (Aves: Emberizidae) $(9,1 \%, \mathrm{n}=11)$. Nenhum animal foi visto consumindo frutos de $P$. nuda. Houve diferença significativa entre o comprimento dos frutos maduros de $P$. nuda $(9,0 \pm 1,1 \mathrm{~mm} ; \mathrm{n}=12)$ e os de $P$. brasiliensis $(10,1 \pm 0,3 \mathrm{~mm} ; \mathrm{n}=12)$, (Teste $\mathrm{t}=2,834 ; \mathrm{p}=0,010 ; \mathrm{gl}=22$ ) que, segundo a classificação de Correia (1997), foram considerados médios e grandes, respectivamente.

$\mathrm{Na}$ área de estudo a densidade de $P$. nuda foi de 144 indivíduos/ha e a de $P$. brasiliensis, de 120 indivíduos/ha. O índice de dispersão de Morisita (ID) indicou valores de ID $=11,45$ para P. nuda e de 3,7 para P. brasiliensis, evidenciando padrão agregado para ambas as espécies. Embora a área não tenha sido escavada, foi constatado um indivíduo de $P$. nuda ligado à planta mãe por uma extensão horizontal de $172 \mathrm{~mm}$ de comprimento (estolão ou rizoma), mas não foram encontradas evidências deste tipo de reprodução em $P$. brasiliensis.

\section{Discussão}

A sincronia na emissão foliar entre os indivíduos de $P$. nuda e $P$. brasiliensis e as correlações significativas desta fenofase com o fotoperíodo, a pluviosidade e a temperatura sugerem estes fatores como possíveis promotores da emissão de folhas novas nas espécies estudadas. Segundo Van Schaik et al. (1993), a produtividade das plantas é potencialmente limitada por conjunto de fatores abióticos: água, luz, gás carbônico e minerais. Por isto pode haver máxima produção em determinado período, evitando a emissão de folhas novas durante estações desfavoráveis. As espécies estudadas podem ser beneficiadas pela maior disponibilidade de nutrientes no solo e pela maior quantidade de luz neste período, pois, segundo Morellato (1992), possivelmente com o aumento da temperatura e da pluviosidade a partir de agosto e setembro, há aumento na decomposição da serrapilheira e como este processo disponibiliza os nutrientes para a vegetação, é provável que as espécies vegetais iniciem suas atividades vegetativa $e$ reprodutiva nesta época. A correlação positiva entre a emissão foliar e as normais climatológicas de pluviosidade para ambas as espécies de Psychotria, mas não com a pluviosidade do período do presente estudo (apenas um ano), sugere que o padrão desta fenofase é ajustado a um padrão de precipitação de longo termo. Entretanto, não se pode descartar que ritmos endógenos sejam fatores determinantes da emissão foliar (Wright \& Calderon 1995).

As três fenofases (emissão foliar, floração e frutificação) não são mutuamente independentes em plantas individuais (Van Schaik et al. 1993). Como as duas populações estudadas mostraram sincronia entre os indivíduos e tiveram sobreposição total no período de emissão de folhas novas, que foi seguido pela produção de botões (obs. pess.), seria esperado que hou- 
vesse sobreposição total do período de floração, a não ser que exista competição por polinizadores entre as duas espécies. A sincronia entre os indivíduos fornece a base para se considerar os eventos fenológicos como adaptações a agentes seletivos bióticos ou abióticos e a ação de fatores bióticos pode levar, tanto à minimização quanto à maximização da sobreposição fenológica entre as espécies de plantas (Van Schaik et al. 1993). O período de floração pode servir como mecanismo de isolamento na especiação de plantas, e a competição por polinizadores pode atuar como força seletiva, estabelecendo e mantendo a divergência sobre o período de floração de espécies vegetais simpátricas (Gentry 1974; Stiles 1975; Campbell 1985; Gottsberger 1986; Newstrom et al. 1994).

$\mathrm{O}$ fato de haver um mês de diferença no maior número médio de flores em ambas as espécies de Psychotria estudadas, pode não ser suficiente para evitar a competição por polinizadores e impedir que cruzamentos interespecíficos aconteçam, até porque a maior percentagem de indivíduos com flores se sobrepôs para ambas as espécies. Diferenças na fenologia de floração entre espécies da mesma família foram registradas em Bignoniaceae (Gentry 1974), Malpighiaceae (Barros 1992), Bromeliaceae (Araújo et al. 1994) e Vochysiaceae (Oliveira \& Gibbs 1994). A interpretação adaptativa freqüentemente utilizada por estes autores é o compartilhamento de polinizadores, isto é, a competição interespecífica pelos polinizadores funciona como força seletiva que causa segregação temporal no período de floração. Mesmo invocando esta hipótese, alguns autores consideram que ela não seja completamente confiável, parcialmente porque análises estatísticas têm mostrado que as diferenças nos períodos de floração são indistinguíveis de padrões aleatórios, e porque tais sistemas geralmente não podem ser testados experimentalmente (Oliveira \& Gibbs 1994). Os dados deste estudo divergem da hipótese de que espécies filogeneticamente próximas e com o mesmo polinizador tendam à segregação temporal do período de floração. As diferentes freqüências de visitação por machos e fêmeas do principal visitante destas espécies (T. glaucopis) pode permitir que elas compartilhem a mesma espécie de polinizador, florescendo na mesma época, sem ter que obrigatoriamente competir por este recurso e divergir a época de floração. Acredita-se que ritmos endógenos ligados a fatores abióticos, como o fotoperíodo, por exemplo, contribuam para a periodicidade no crescimento (emissão foliar) deste gênero (Wright \& Calderon 1995) e que a floração das duas espécies seja sobreposta influenciada pelas relações filogenéticas entre elas (Wright 1991).

A correlação negativa entre o número de flores abertas em P. brasiliensis e o fotoperíodo corrobora a observação de que a atividade de polinizadores invertebrados diurnos, como borboletas e abelhas, é provavelmente limitada pelo comprimento do dia (Grandisoli 1997). Este fato poderia explicar, parcialmente, porque $P$. brasiliensis foi 2,7 vezes menos visitada por insetos do que $P$. nuda, apesar da primeira espécie possuir algumas características mais próximas à entomofilia do que a segunda, como corola tubular de cor amarelo-clara, quase branca.

O extenso período de frutificação das espécies pode ser explicado pela hipótese de McKey (1975 apud Howe \& Smallwood 1982), em que plantas tropicais com períodos de frutificação longos, limitam a produção de frutos maduros, com polpas ricas e poucas sementes grandes. Deste modo, estas espécies restringem a dispersão de suas sementes por aves especializadas, aptas a procurar recurso alimentar raro, mas excepcionalmente nutritivo. Estas são denominadas plantas de alto investimento e estendem a frutificação para evitar que um número limitado de especialistas se saciem, promovendo, assim, maior dispersão de sementes, ao longo do tempo, por forrageadores eficientes. Algumas espécies vegetais tolerantes à sombra nos estádios juvenis, como as Psychotria estudadas, tendem a produzir frutos e sementes 
maiores que espécies pioneiras, como algumas do gênero Miconia, por exemplo. Essas espécies dependem do material contido nos tecidos de reserva do fruto e da semente para atrair seu dispersor e promover o desenvolvimento da plântula nas condições de sub-bosque (PiñaRodrigues \& Aguiar 1993).

Lipaugus lanioides deve ser o principal dispersor das sementes de P. brasiliensis, pois as espécies do gênero Lipaugus estão entre os principais frugívoros especialistas de florestas tropicais (Snow 1981) e, juntamente com os demais membros da família Cotingidae, são importantes agentes dispersores de sementes (Snow 1971). Baryphthengus ruficapillus é uma espécie generalista (Sick 1997) que pode ser considerado potencial dispersor de $P$. brasiliensis, e Saltator similis é espécie granívora (Sick 1997), portanto deve ser predador de sementes desta espécie. Devido ao tamanho dos frutos maduros (grandes - sensu Correia 1997) associado à produção de sementes (duas por fruto), à pequena disponibilidade de frutos maduros e à maior freqüência de ingestão destes por um frugívoro especialista, considera-se que $P$. brasiliensis se encaixa no modelo de alto investimento (McKey 1975 apud Howe \& Smallwood 1982).

Em outubro e novembro houve decréscimo tanto da média de frutos maduros por planta, quanto da percentagem de indivíduos com frutos maduros para P. nuda e P. brasiliensis. Isto pode ser resultado da alta taxa de forrageamento de aves no período inicial da fase reprodutiva, que no Brasil é geralmente entre setembro e janeiro (Sick 1997).

Explicação alternativa para o extenso período de frutificação seria a de que, além da dispersão, as angiospermas têm também que defender seus frutos contra o dano causado por herbívoros (Krebs 1994). As plantas podem reduzir o tempo de exposição dos frutos maduros, permanecendo com frutos verdes por muitos meses, amadurecendo aos poucos ao longo do período de frutificação (Howe \& Smallwood 1982). A interação entre predadores e dispersores de sementes com as plantas influenciam no modo de produção, no valor nutritivo e na apresentação temporal dos frutos (Krebs 1994).

Segundo a classificação de Newstron et al. (1994), as populações das duas espécies de Psychotria possuem ciclos fenológicos anuais, exceto para a frutificação, cujo ciclo é contínuo. A duração do episódio de floração é do tipo intermediária ("intermediate flowering") (Newstron et al. 1994), categorizada pela presença de flores de um até cinco meses.

Os valores obtidos para o índice de dispersão padronizado de Morisita (ID) indicam que os indivíduos de $P$. nuda e de $P$. brasiliensis possuem distribuição espacial do tipo agregada. A distribuição do tipo agregada pode ser explicada por alguns fatores, como a germinação preferencial em sítios mais favoráveis ao desenvolvimento, a reprodução vegetativa e a distância de dispersão (Silvertown 1987).

Pelas observações de campo, há indícios de que o tipo de distribuição espacial encontrada para $P$. nuda deve-se, pelo menos em parte, ao crescimento clonal, devido ao registro na área de estudo de um indivíduo desta espécie ligado à planta mãe. Mesmo não tendo sido encontradas evidências de reprodução vegetativa em $P$. brasiliensis, é possível que este tipo de reprodução ocorra também nesta espécie, pois, além da proximidade filogenética com $P$. nuda, esta é uma estratégia reprodutiva evolutivamente antiga e muito difundida entre os diferentes táxons de plantas (Silvertown 1987). Portanto, a ocorrência de reprodução sexuada e vegetativa em P. nuda e, possivelmente, em P. brasiliensis sugere que as espécies possam utilizar uma ou outra estratégia, dependendo das condições ambientais. Acredita-se que mesmo com a baixa taxa de remoção de frutos por aves observada neste estudo, os propágulos não se acumulam próximo à planta mãe, o que aumentaria a agregação entre os indivíduos, pois em estudos de biomassa de frutos no local, as freqüências de frutos de $P$. nuda e P. brasiliensis coletados 
no solo foram próximas de zero (M.B.Vecchi com. pess. e obs.pess.).

Mais estudos são necessários para esclarecer as relações entre as espécies de Psychotria e seus agentes dispersores. A agregação entre os indivíduos pode ser fator importante na polinização de plantas que disponibilizam poucas flores por dia, como as espécies estudadas. A agregação de indivíduos possibilita a concentração de maior número de flores em determinado local, aumentando a atratividade e com isso aumenta a probabilidade de visitas e, conseqüentemente, a polinização por beija-flores (Feinsinger et al. 1991). Grandisoli (1997) estudando Psychotria suterella também encontrou distribuição espacial agregada para esta espécie. Este autor considerou este padrão importante no aumento da atração visual e olfativa dos agentes polinizadores, principalmente abelhas do gênero Bombus.

Os resultados do presente estudo sugerem que ambas as espécies de Psychotria constituem importante recurso para espécies de aves de Floresta Atlântica.

\section{Agradecimentos}

Este estudo é parte dos resultados do Programa de Ecologia, Conservação e Manejo de Ecossistemas do Sudeste Brasileiro, Setor de Ecologia da Universidade do Estado do Rio de Janeiro (UERJ).

Os Autores agradecem ao pessoal do Centro de Estudos Ambientais e Desenvolvimento Sustentável - CEADS no Campus Regional da UERJ na Ilha Grande e da Coordenadoria de Campi regionais - CCR; à Sub-Reitoria de Pósgraduação e Pesquisa SR-2 e FAP/SR; ao professor Mário Gomes (Universidade Federal do Rio de Janeiro) que identificou as espécies vegetais; aos professores Johan Becker (Museu Nacional do Rio de Janeiro) e Favízia (Universidade Federal do Paraná), pela identificação das abelhas e, a Marcelo Duarte (UFPR), pela identificação das borboletas; à Fundação Instituto de Desenvolvimento Econômico e Social do Rio de
Janeiro, pelos dados de normal fornecidos; a C. F. D. Rocha, M. Van Sluys e H. G. Bergallo, pelo auxílio com sugestões e críticas ao trabalho; aos colegas A. L. Storni, A. F. N. Freitas, M. Vecchi, P. D. Ritter e R. V. Marques, pela ajuda no trabalho de campo. A Fábio R. Scarano e a dois revisores anônimos, por valiosas sugestões ao texto. Ao Conselho Nacional de Desenvolvimento Científico e Tecnológico - CNPq pela concessão de bolsa de Mestrado à primeira autora, (Processo 131560/1998-0) e de Produtividade em Pesquisa para a segunda autora (Processo $\mathrm{N}^{\mathrm{o}} 301$ 524/88-2).

\section{Referências bibliográficas}

Aide, T. M. \& Angulo Sandoval, P. 1997. The effect of dry season irrigation on leaf phenology and the implications for herbivory in a tropical understory community. Caribbean Journal of Science 33: 142-149.

Almeida, D. R.; Carvalho, L. C. \& Rocha, C. F. D. 1998. As Bromeliáceas da Mata Atlântica da Ilha Grande, RJ: composição e diversidade de espécies em três ambientes diferentes. Bromélia 5(1-4): 54-65.

Altmann, J. 1974. Observational study of behavior: sampling methods. Behavior 49: 227-265.

Araújo, A.C.; Fisher, E. A. \& Sazima, M. 1994. Floração seqüencial e polinização de três espécies de Vriesea (Bromeliaceae) na região de Juréia, sudeste do Brasil. Revista Brasileira de Botânica 17: 113-118.

Araújo, D. S. D. \& Oliveira, R. R. 1988. Reserva Biológica Estadual da Praia do Sul (Ilha Grande, Estado do Rio de Janeiro): lista preliminar da flora. Acta Botanica Brasilica 1: 83-94.

Barros, M. A. G. 1992. Fenologia da floração, estratégias reprodutivas e polinização de espécies simpátricas do gênero Byrsonima Rich (Malpighiaceae). Revista Brasileira de Biologia 52(2): 343-353.

Bawa, K. S. 1990. Plant-pollinator interactions in Tropical Rain Forest. Annual Review of Ecology and Systematic 21: 399-422. 
Borchert, R. 1983 Phenology and control of flowering in tropical trees. Biotropica 15(2): 81-89.

Brower, J. E. \& Zar, J. H. 1984. Field and laboratory methods for general ecology. 2nd. ed. W.C. Brown Publishers, Iowa.

Campbell, D. R. 1985. Pollinator sharing and seed set of Stellaria pubera: competition for pollination. Ecology 66: 544-553.

Correia, J. M. S. 1997. Utilização de espécies frutíferas da Mata Atlântica na alimentação da avifauna da Reserva Biológica de Poço das Antas, R.J. Dissertação de Mestrado.Universidade de Brasília, Brasília.

Feinsinger, P.; Swarm, L. A. \& Wolfe, J. A. 1985. Nectar - feeding birds on Trinidad and Tobago: comparison of diverse and depauperate guilds. Ecological Monographs 55(1): 1-28.

Feinsinger, P.; Tiebout III, H. M. \& Young, B. E. 1991. Do tropical bird-pollinated plants exhibit densitydependent tnteractions? Field experiments. Ecology 72: 1953-1963.

Galetti, M. \& Pizo, M. A. 1996. Fruit eating by birds in a forest fragment in Southeastern Brazil. Ararajuba 4(2): 71-79.

Gentry, A. H. 1974. Flowering phenology and diversity in tropical Bignoniaceae. Biotropica 6(1): 64-68.

Gottsberger, G. 1986. Some pollination strategies in neotropical savannas and forests. Plant Systematic Evolution 152(29): 30-45.

Grandisoli, E. A. C. 1997. Biologia reprodutiva e estrutura da população de Psychotria suterella Muell. Arg. (Rubiaceae) em um fragmento de mata secundária em São Paulo (SP). Dissertação de Mestrado. Universidade de São Paulo, São Paulo.

Howe, H. F. \& Primack, F. B. 1975. Differential seed dispersal by birds of the Casearia nitida (Flacourtiaceae). Biotropica 7(4): 278-283.

Howe, H. F. \& Smallwood, J. 1982. Ecology of seed dispersal. Annual Review of Ecology and Systematic 13: 201-228.

Ibarra Manriquez, G. \& Sinaca Colin, S. 1995. Commented checklist of plants from the "Los Tuxtlas" Biological Station, Veracruz, Mexico. Revista de Biologia Tropical 43: 75-115.

Krebs, C. J. 1994. Ecology: the experimental analysis of distribution and abundance. 4th. ed. Harper Collins, New York.

Lima, H. A. 1988. Heterostilia em Psychotria leiocarpa Cham. \& Schl. (Rubiaceae). Boletim do Museu Nacional 76: 1-16.
Morellato, L. P. C. 1990. Estratégias fenológicas de espécies arbóreas em floresta de altitude na Serra do Japi, Jundiaí, São Paulo. Revista Brasileira de Biologia 50(1): 149-162.

Morellato, L. P. C. 1992. Sazonalidade e dinâmica de ecossistemas florestais na Serra do Japi.Pp. 98110. In: L. P. C. Morellato (Org.), História natural da Serra do Japi: ecologia e preservação de uma área florestal no sudeste do Brasil. Editora da Unicamp, Campinas.

Morellato, L. P. C. \& Leitão-Filho, H. F. 1992. Padrões de frutificação e dispersão na Serra do Japi. Pp. 112-140. In: L. P. C. Morellato (Org.), História natural da Serra do Japi: ecologia e preservação de uma área florestal no sudeste do Brasil. Editora da Unicamp, Campinas.

Newstron, L. E.; Frankie, G. W. \& Baker, H. G. 1994. A new classification for plant phenology based on flowering patterns in Lowland Tropical Rain Forest Trees at La Selva, Costa Rica. Biotropica 26: 141-159.

Oliveira, P. \& Gibbs, P. 1994. Pollination biology and breeding systems of six Vochysia species (Vochysiaceae) in Central Brazil. Journal of Tropical Ecology 10: 509-522.

Pachecho, S. \& Grau, R. 1997. Phenology of an understory shrub and bird-dispersal in relation to tree-fall gaps in a subtropical montane forest of Northwest Argentina. Ecologia Austral 7: 35-41.

Piña-Rodrigues, F. C. M. \& Aguiar, I. B. 1993. Maturação e dispersão de sementes. Pp. 215-274. In: I. B. Aguiar, F. C. M. Piña-Rodrigues \& M. B Figliolia (Eds.). Sementes Florestais Tropicais. Associação Brasileira de Tecnologia de Sementes, Brasília.

Sick, H. 1997. Ornitologia Brasileira. Editora Nova Fronteira, Rio de Janeiro.

Silvertown, J. 1987. Introduction to plant population ecology. 2nd. ed. Longman Scientific \& Technical, New York.

Snow, D. W. 1971. Evolutionary aspects of fruit-eating by birds. Ibis 113: 194-202.

Snow, D. W. 1981. Tropical frugivorous birds and their food plants: a world survey. Biotropica 13(1): 114.

Stiles, F. G. 1975. Ecology, flowering phenology, and hummingbirds pollination of some Costa Rican Heliconia species. Ecology 56: 285-301.

Tissue, D. T. \& Wright, S. J. 1995. Effect of seasonal water availability on phenology and the annual shoot carbohydrate cycle of tropical forest shrubs. Functional Ecology 9: 518-527 
Van Schaik, C. P.; Terborgh, J. W. \& Wright, S. J. 1993. The phenology of Tropical Forests: adaptative significance and consequences for primary consumers. Annual Review of Ecology and Systematic 24: 353-377.

Wright, S. J. 1991. Seasonal drought and the phenology of understory shrubs in a Tropical Moist Forest. Ecology 72: 1643-1657.
Wright, S. J. \& Calderon, O. 1995. Phylogenetic patterns among tropical flowering phenologies. Journal of Ecology 83: 937-948.

Zar, J. H. 1999. Biostatistical analysis. 4th. ed. Prentice-Hall, New Jersey. 